\title{
POTENSI WILAYAH PERBATASAN STRATEGIS
}

\author{
Mimin Sundari Nasution \\ FISIP Universitas Riau, Kampus Bina Widya Km. 12,5 Simpang Baru Panam, Pekanbaru 28293
}

\begin{abstract}
Strategic Border Area Potential. Pasir Limau Kapas Sub-district [Palika], Rokan Hilir District, Riau Province is an area that is left behind, isolated and outermost. This position causes welfare to become an important and main issue that is always a subject of discussion. Key and important issues related to welfare include, at the very least, slow and slow development of infrastructure, ambiguous development policies [overlapping policies that are not mutually supportive in relation to development in border areas], omission of territorial violations and fishing equipment, defense issues- State border security that has not yet become a major concern and potential of unexplored natural attractions. Based on various important issues, this research aims, first, to explain the main potential of Pasir Limau Kapas as a strategic border area. The approach used is qualitative with descriptive analysis method. Data is collected based on documents supported by interviews. After collecting data analyzed qualitatively. This study concludes that, first, the main potential possessed by Pasir Limau Kapas, such as the geographical position related to the strategic area and the resulting regulation, is considered not to support the defense and security issues of the border country, including developing the potential area of natural attractions. The development of border areas which are considered strategic is sure to require devices in the area that will manage them.
\end{abstract}

Abstrak: Potensi Wilayah Perbatasan Strategis. Kecamatan Pasir Limau Kapas [Palika], Kabupaten Rokan Hilir, Provinsi Riau merupakan kawasan yang tertinggal, terisolir dan terluar. Posisi ini menyebabkan kesejahteraan menjadi isu penting dan utama yang selalu menjadi bahan diksusi. Isu penting dan utama terkait kesejahteraan antara lain, pembangunan infrastruktur yang minim dan lambat, kebijakan pembangunan yang ambigu [rerata kebijakan yang dikeluarkan saling tumpang-tindih tidak saling mendukung terkait pembangunan di kawasan perbatasan], pembiaran pelanggaran wilayah dan alat penangkapan ikan, masalah pertahanan-keamanan batas negara yang belum menjadi perhatian utama dan potensi objek wisata alam yang belum tergarap. Berdasarkan berbagai isu penting, penelitian ini bertujuan menjelaskan potensi utama yang dimiliki Pasir Limau Kapas sebagai kawasan perbatasan yang strategis. Pendekatan yang digunakan adalah kualitatif dengan metode analisis deskriptif. Data dikumpulkan berdasarkan dokumen yang didukung wawancara. Setelah terkumpul data dianalisis secara kualitatif. Studi ini menyimpulkan bahwa, pertama, potensi utama yang dimiliki Pasir Limau Kapas, seperti posisi geografis terkait kawasan strategis dan regulasi yang dihasilkan dinilai belum mendukung masalah pertahanan dan keamanan negara di perbatasan termasuk mengembangkan kawasan potensi objek wisata alam. Pengembangan kawasan perbatasan yang dinilai strategis dipastikan memerlukan perangkat di daerah yang akan mengelolanya.

Kata Kunci: potensi, wilayah perbatasan, pengembangan

\section{PENDAHULUAN}

Penelitian ini berupaya menelaah terkait pengembangan wilayah dan hubungan dengan pembangunan kawasan perbatasan yang dinilai strategis. Telaahan dimaksudkan sebagai upaya mengidentifikasi dan menjelaskan potensi utama serta peran pemerintah Kabupaten Rokan Hilir yang didukung pemerintah provinsi dan pemerintah pusat mengembangkan kawasan perbatasan di Kecamatan Pasir Limau Kapas [Palika] Kabupaten Rokan Hilir di Provinsi Riau.

Terkait dengan kawasan perbatasan sudah menjadi hal biasa apabila hampir semua kawasan perbatasan Indonesia adalah daerah tertinggal, dan terisolir yang kondisinya memprihatinkan sebagai wajah luar negara. Kawasan perbatasan Indonesia sebagai wajah luar negara terkesan jika pengelolaanya lebih mengedepankan pendekatan keamanan (safety belt approach). Sehingga pembangunan sosial, ekonomi, infrastruktur dan yang lainnya terkesan menjadi terabaikan. Menyadari realitas kawasan perbatasan yang merupakan permasalahan serius, maka Pemerintah Pusat sejak 28 Januari 2010, membentuk Badan 
Nasional Pengelola Perbatasan (BNPP). Pada pemerintahan pusat, instusi ini berfungsi mengkoordinasi dan mengimplementasikan program-program pemerintah membangun kawasan perbatasan tersebut.

Dalam hubungan ini pula, maka pengembangan kawasan perbatasan dinilai inheren dengan nawacita ke-3 presiden dan wakil presiden tahun 2015, yakni, “Membangun Indonesia dari pinggiran dengan memperkuat daerahdaerah dan desa dalam kerangka Negara Kesatuan”. Dalam konteks hubungan dengan politik desentralisasi maka Nawacita ini memberikan jastifikasi dimulainya apa yang dikenal dengan Desentralisasi Asimetris. Dari sini terdapat 5 arah kebijakan pengembangan Desentralisasi Asimetris yakni: [1] Penguatan tata kelola dan peningkatan kualitas pemerintahan daerah; [2]. Pembangunan Desa dan Kawasan Perdesaan; [3]. Pembangunan daerah tertinggal; [4]. Pengembangan kawasan perbatasan; [5]. Penataan Daerah Otonomi Baru [DOB] untuk kesejahteraan masyarakat.

Secara substansi dalam pemahaman Desentralisasi Asimetris ini kawasan perbatasan dinilai perlu mendapatkan perlakuan khusus mengingat perannya sebagai batas kedaulatan negara. Kawasan perbatasan memegang fungsi penting karena kompleksitas masalah yang dihadapi dan daerah perbatasan harus menjadi halaman depan Negara. Citra sebagai halaman depan negara yang sampai saat ini masih terus diperjuangkan.

Pada konteks lain, pengembangan kawasan perbatasan sesuai dengan target yang ada di dalam Sasaran Pembangunan Kewilayahan dan Antarwilayah dalam RPJMN 2015-2019, pembangunan kawasan perbatasan difokuskan pada pengembangan pusat ekonomi perbatasan di 10 Pusat Kawasan Strategis Nasional(PKSN), dan 187 lokasi prioritas [Lokpri] serta peningkatan keamanan dan kesejahteraan masyarakat perbatasan di 92 pulau-pulau kecil terluar dan terdepan. Ada tiga dimensi yang diterapkan dalam usaha pencapaian target tersebut, kesejahteraan, keamanan dan lingkungan.

Dalam konteks pencapaian ketiga dimensi tersebut justru yang menjadi persoalan utamanya sebagai kawasan strategis yang letaknya diperbatasan, Kecamatan Pasir Limau Kapas [Palika], Kabupaten Rokan Hilir, Provinsi Riau, persoalan kesejahteraan dan keamanan menjadi isu utama yang selalu diperbincangkan. Selain itu pembangunan infrastruktur wisata menjadi keinginan pemerintah daerah yang sangat kuat secara terus menerus untuk dikembangkan.

Berdasarkan berbagai argumentasi yang telah dikemukakan inilah, maka pengembangan kawasan perbatasan Palika sebagai kawasan studi, paling tidak terdapat beberapa alasan yang mendukungnya. [a] Palika merupakan kecamatan yang ibu kotanya Panipahan satu-satunya di kabupaten Rokan Hilir [Rohil], atau Provinsi Riau yang tidak dapat diakses melalui jalan darat, padahal letaknya masih di pulau Sumatera. [b]. Satu-satunya kecamatan yang terjadi konflik perbatasan secara langsung dengan negara tetangga, Malaysia, dan Provinsi tetangga Sumatera Utara. [c]. Palika belum menjadi skala prioritas pengembangan perbatasan sesuai RJPMD Rokan Hilir. [d]. Badan Pengelola Perbatasan [BPP] yang ada telah dilikuidasi tahun 2016, setelah didirikan tahun 2014, sebagai dampak peraturan pemerintah tentang perangkat daerah.

Berbagai alasan ini mendukung secara akademis jika studi ini dapat berkontribusi,

a) Menciptakan pemerataan kajian kawasan perbatasan strategis yang hanya tertumpu seputar Kalimantan, dan Riau Kepulauan [Batam-Bintan-Karimun]. Hasil penelitian ini bermanfaat untuk memperkaya dan memperdalam studi mengenai pengembangan [pembangunan] kawasan perbatasan utamanya yang strategis.

b) Sebagai bahan perbandingan jika regulasi menyebabkan pengelolaan Pulau Batam yang tumpang-tindih kewenangan [sampai sekarang belum selesai], sementara di kabupaten Rokan Hilir, Badan Pengelola Perbatasan [BPP] dihapuskan. Hasil penelitian ini secara praktis bermanfaat untuk membantu pemerintah pusat, pemerintah provinsi, pemerintah kabupaten dan wilayah administratif daerah Kecamatan Pasir 
Limau Kapas dalam membuat kebijakan terkait pengembangan kawasan perbatasan.

Berpedoman pada latar belakang ini, maka permasalahan yang dirumuskan dalam bentuk pertanyaan penelitian adalah: Apa saja potensi utama yang dimiliki Palika sebagai kawasan perbatasan strategis? Oleh karena itu tujuan dari penelitian ini adalah Menjelaskan potensi utama yang dimiliki Palika sebagai kawasan perbatasan strategis.

Dalam berbagai studi pengembangan kawasan perbatasan khususnya pada daerah yang dinilai strategis [termasuk pada studi ini], perlu mendapat perhatian yang serius, terpokus, dan terintegrasi. Oleh karena itu wilayah perbatasan [Border area] dengan sinonim yang sama cross-border area secara luas berkaitan dengan heterogenitas spasial dalam istilah struktur ekonomi, politik dan sumber daya yang terdiri atas dua atau lebih kekuasaan (Joyodipuro, 1992; Blair 1995; Henrikson, 2000).

Berkaitan dengan perwujudan fisik batas wilayah perbatasan, menurut Guo (2004), batas wilayah dapat dibagi menjadi pendekatan. [a]. Natural Border, yaitu wilayah dibatasi oleh batas alam seperti gunung, sungai, danau, laut, pantai, atau selat. Karena urgensinya terhadap kepentingan pertahanan batas tersebut seringkali dianggap sebagai batas politik. [b]. Artificial Border, yaitu batas wilayah yang dapat terdiri dari batas buatan (batu, dinding), batas geometris (menggunakan batas koordinat bumi), dan batas cultural/budaya (perbedaan budaya, etnis dan ideologi).

Berbagai literatur menyebutkan jika kawasan perbatasan negara adalah wilayah yang memiliki posisi strategis [Rodrigues, 1996). Oleh karena kedaulatan menjadi isu strategis kawasan perbatasan sebagai beranda depan negara (Herikson, 2000). Perlu dimengerti jika kawasan perbatasan negara terkandung potensi strategis [utama], berupa tapal batas wilayah kedaulatan, pertahanan dan keamanan serta pemanfaatan pengelolaan berbagai sumberdaya untuk pembangunan (Joyodipuro, 1992).

Dalam hubungan potensi utama di Palika adalah posisi geografis, kebijakan pemerintah pusat, perencanaan, investasi, pembangunan infrastruktur, hukum pertahanan keamanan (Nugroho dan Danuri 2004). Konteks pada penelitian ini, di Palika terdapat empat hal potensi utama yang dinilai menonjol, seperti posisi geografis, regulasi terkait kawasan perbatasan, hukum pertahanan kemananan dan potensi wisata alam.

Berdasarkan penjelasan potensi utama pada kawasan perbatasan yang strategis menjadi penting mengetahui keberadaan [peran] pemerintah dalam hal ini tentunya Pemerintah Daerah [Pemerintah Kabupaten Rokan Hilir]. Dalam banyak literatur menunjukan bahwa peran atau juga disebut dengan fungsi pemerintah diklasifikasi menjadi fungsi primer dan skunder (Rasyid, 2000) .

Primer dimaknai sebagai fungsi pelayanan dan pengaturan (Rasyid, 2000) dan (Kencana, 2013). Fungsi Primer merupakan fungsi pemerintah yang berjalan terus-menerus dan memiliki hubungan positif dengan kondisi masyarakat yang diperintah. Maksudnya adalah fungsi primer dijalankan secara konsisten oleh pemerintah, tidak terpengaruh oleh kondisi apapun, tidak berkurang dan justru semakin meningkat jika kondisi masyarakat yang diperintah meningkat. Fungsi primer dibedakan menjadi Pelayanan dan Pengaturan.

Sementara pada sisi lain, fungsi sekunder peran pemerintah adalah pembangunan dan pemberdayaan. Dalam hubungan ini memperjelas peran pemerintah [daerah], misalnya dapat dimengerti jika pengelolaan kawasan perbatasan merupakan tanggung jawab yang wajib dilaksanakan dalam hal ini pemerintah daerah. Sebagai konsekwensinya, pemerintah yang di atasanya, pemerintah provinsi dan pemerintah pusat mempunyai kewajiban mendukung. Jadi dalam hal ini pemerintah terintergasi antara satu dengan yang lainnya (Aminah 2014; Rasyid 2000).

\section{METODE}

Penelitian ini menggunakan pendekatan kualitatif, dimana peneliti menelaah pengembangan kawasan perbatasan dengan melakukan pengamatan di lapangan lebih mendalam terhadap unit analisis yang diteliti sehingga 
data yang didapat lebih akurat sesuai alur penelitian. Lokasi pengumpulan data dalam penelitian ini adalah Kecamatan Pasir Limau Kapas dalam konteks wilayah administratif. Sementara pengumpulan data juga dilakukan di wilayah Bagansiapiapi sebagai ibu kota kabupaten Rokan Hilir.

Jenis data yang dibutuhkan dalam penelitian ini adalah data primer dan data sekunder. Data primer diperoleh berdasarkan sumber pimer melalui informan. Informan ditentukan dengan teknik purposif. Artinya dalam konteks penelitian ini informan dipilih berdasarkan informasi dan kewenangan yang dimilikinya dan keterlibatan dalam permasalahan penelitian yang sedang ditelaah. Sementara data sekunder, data yang diperoleh dari sumber kedua seperti hasil laporan, buku-buku, jurnal, peraturan perundang-undangan dan berita di media cetak maupun elektronik.

Teknik pengumpulan data dalam penelitian ini dilakukan dengan cara penelitian lapangan dan wawancara terhadap sejumlah informan mengenai pengembangan [pembangunan], permasalahan dan yang lainnya sesuai yang akan dikaji dalam penelitian ini. Teknik pengumpulan data yang digunakan peneliti adalah wawancara. Wawancara dilakukan mendalam dan terfokus pada tujuan yang hendak dijawab pada penelitian ini.

Selain itu, teknik pengumpulan data juga dilakuan dengan melaksanakan Fokus Grup Diskusi. Cara ini untuk lebih membantu juga mengefentifkan secara langsung diskusi perihal pengembangan kawasan perbatasan startegis. Kesemuanya dalam kerangka mengumpulan data untuk kepentingan penelitian Sebagai penelitian kualitatif maka teknis analisis data dalam penelitian ini melalui tiga alur kegiatan yakni berupa reduksi data, penyajian data dan penarikan kesimpulan setelah dilakukan verifikasi atau pembuktian.

\section{HASIL DAN PEMBAHASAN}

Potensi utama yang dimiliki Pasir Limau Kapas [Palika] sebagai kawasan perbatasan strategis yang menonjol adalah posisi geografis, regulasi terkait pembangunan perbatasan, hukum, pertahanan-keamanan negara dan potensi keindahan alam. Keempat potensi ini yang akan menjadi pembahasan sebagai wujud menjelaskan terkait salah satu prinsip dalam pengembangan kawasan khususnya kawasan perbatasan yang dinilai strategis.

\section{Posisi Geografis}

Posisi geografis merupakan potensi utama sebuah wilayah, daerah atau kawasan yang dapat dinilai menjadi kawasan yang berpotensi atau tidak secara strategis. Dalam hubungan ini, keberadaan Pasir Limau Kapas tidak jauh berbeda dengan Pulau Batam yang dinilai strategis karena berdekatan dengan Singapura (Albintani 2016). Sementara di Palika melalui posisi Panipahan sebagai ibu kota, dan Pulau Jemur yang langsung berada di Selat Melaka.

Secara sangat sederhana berdasarkan dari argumentasi tersebut menunjukkan bahwa Palika tidak jauh berbeda dengan Pulau Batam. Rencana pembangunan jembatan (MelakaDumai] memperjelas posisi Palika sebagai kawasan perbatasan yang strategis. Temuan studi ini juga sebagai bukti bahwa pada konteks ini, pemerintah [pusat dan daerah] berada pada posisi belum mampu mengembangkan wilayah strategis Palika.

2. Regulasi Terkait Pengembangan Kawasan Perbatasan

Berbagai regulasi atau pun aturan yang dikeluarkan di kawasan perbatasan merupakan potensi utama yang juga perlu menjadi bahan kajian untuk dijelaskan. Temuan studi ini menunjukkan jika berbagai regulasi terkait pengembangan kawasan perbatasan menimbulkan kebijakan yang saling berlawanan. Akibatnya bagi pemerintah daerah kabupaten Rokan Hilir menetapkan kebijakan yang ambigu: bertolak belakang. Terkait dengan kebijakan ini dapat dicermati setelah didirikan Badan Pengelola Perbatasan [Perda No.10/ 2013]. Kemudian, berdasarkan Perda No.11/ 2016, Badan Pengelola Perbatasan ditiadakan [dilikuidasi].

Realita temuan studi dapat dicermati berdasarkan kronologis berbagai kebijakan yang ada. Regulasi dimulai dengan Pembentukan Badan Nasional Pengelola Perbatasan (BNPP) melalui : 
a) Perpres No.12/2010 [menyusun Grand Design] dan Rencana Induk Pengelolaan Batas Wilayah Negara dan Kawasan Perbatasan. Kemudian melalui amanat Nawa Cita

b) Perpres No.2/2015 tentang, "Rencana Pembangunan Jangka Menengah Nasional (RPJMN) 2015-2019 [peletakan dasardasar dimulainya Desentralisasi Asimetris".

c) Permendagri No.2/2011 tentang, "Pedoman Pembentukan Badan Pengelola Perbatasan di Daerah”.

d) Peraturan Kepala BNPP No.1 Tahun 2015tentang, "Rencana Induk Pengelolaan Perbatasan Negara Tahun 2015-2019”.

e) Perda Provinsi Riau No.3 Tahun 2014 tentang, “Organisasi Inspektorat, Badan Perencanaan Pembangunan Daerah dan Lembaga Teknis Daerah Provinsi Riau”.

f) Peraturan Gubernur Provinsi Riau No. 21 Tahun 2015 tentang, "Rincian Tugas, Fungsi dan Tatakerja Badan Pengelola Perbatasan Daerah Provinsi Riau melakukan penyusunan Renduk PBWNKP”.

g) Peraturan Daerah No.10 Tahun 2013 tentang, "Badan Pengelola Perbatasan Kabupaten Rokan Hilir”.

h) Peraturan Pemerintah No.18 Tahun 2016 tentang, "Perangkat Daerah".

i) Peraturan Daerah No.11 Tahun 2016 tentang, "Pembentukan Perangkat Daerah Kabupaten Rokan Hilir”.

Temuan studi ini berdasarkan kronologis berbagai kebijakan yang dikeluarkan tersebut menemukan bahwa antar kebijakan dapat meniadakan institusi yang mengelola perbatasan. Padahal dalam hasil kajian Desentralisasi Asimetris (Bappenas 2016), pada kesimpulan kedua menegaskan bahwa mengembangkan kebijakan penataan kewenangan dan kelembagaan dalam penyelenggaraan pemerintah di kawasan perbatasan negara, merupakan strategi penguatan kewenangan dan kelembagaan kecamatan di perbatasan.

Dalam hubungan ini dapat dipahami jika pentingnya penguatan kecamatan sesuai dengan amanat UU No. 43 Taun 2008 tentang,
"Wilayah Negara”, serta UU No.23 Tahun 2014 tentang, "Pemerintahan Daerah", yang mana peran kewenangan dan kelembagaan dalam penyelenggaraan pemerintahan di kawasan perbatasan negara berada di tangan camat [di kecamatan].

Namun dari berbagai kebijakan ini justru saling meniadakan yang berdasarkan temua studi ini tidak menjadi perhatian pemerintrah daerah. Secara riil, misalnya, Peraturan Daerah No.10 Tahun 2013 tentang, "Badan Pengelola Perbatasan Kabupaten Rokan Hilir”, justru seolah-olah dilikuidasi sebagai dampak dari diterbitkannya Peraturan Pemerintah No. 18 Tahun 2016 tentang, "Perangkat Daerah”.

Kebijakan pemerintah pusat tentang perangkat daerah menjadi jastifikasi dilikuidasinya Badan Pengelola Perbatasan Kabupaten Rokan Hilir sesuai dengan tugas dan fungsi yang diembannya dalam kerangka efektivitas dan efiensi anggaran. Pemerintah Pusat melalui Kementeraian Menteri Dalam Negeri telah menetapkan struktur organisasi perangkat daerah. Struktur ini yang akan menjadi pedoman bagi daerah dalam penetapan struktur organisasi di daerah.

3. Hukum, Pertahanan dan Keamanan Negara Selain posisi geografis, berbagai regulasi atau pun aturan yang dikeluarkan di kawasan perbatasan, hukum [perlakuan atau pelanggaran terhadap aturan merupakan kejahatan], Pertahanan dan Keamanan, merupakan potensi utama yang juga perlu untuk dijelaskan. Ini disebabkan perlakuan hukum, pertahanan dan keamanan sangat mempengaruhi upaya pengembangan sebuah kawasan perbatasan. Secara inheren dalam hal potensi utama ini adalah tindak lanjut yang terkait dengan persoalan krusial kedaulatan negara.

Temuan studi ini terkait hukum, pertahanan dan keamanan negara menunjukan bahwa perubahan kebijakan dan pengalaman konflik dengan Malaysia terdapat sudut pandang yang berbeda atas tanggapan dalam pemerintahan. Pemerintah pusat sejauh ini belum menunjukkan perhatian jika Pasir Limau Kapas merupakan kawasan perbatasan strategis yang perlu dilindungi. 
Sementara pada sisi lainnya, berkurangnya kewenangan kabupaten dalam batas tertentu [kewenangan pengawasan laut], menyebabkan pengawasan menjadi seolah-olah terbiarkan. Belajar dari kehilangan Pulau Simpadan dan Pulau Ligitan bagi daerah menjadi pelajaran berharga.

Dalam hubungan kehilangan ini, peristiwa klaim Malaysia terhadap Pulau Jemur tidak juga menjadi pelajaran berharga bagi pemerintah pusat, sementara bagi pemerintah daerah berbeda sekali. Bagi daerah kehilangan Simpadan dan Ligitan memberikan pelajaran berharga jika warga yang mendiami pulau tersebut berhati-hati. Jangan sampai kehilangan Pulau yang di klaim seperti Simpadan dan Ligitan di Kalimantan.

Bagi Palika, Pulau Jemur sebagai pulau terluar yang juga memiliki keindahan potensi alam yang menawan dapat membawa implikasi negatif. Apalagi pernah terjadi klaim oleh pemerintah Malaysia. Ini terkait dengan kedaulatan. Pada konteks yang lain, studi menemukan bahwa seolah-olah terjadi pembiaran terkait praktik 'pencurian ikan' dikawasan ini oleh nelayan luar dengan menggunakan pukat Harimau. Padahal kejadian ini sudah beberapa kali dikomplain, kemudian dilakukan pelaporan oleh masyarakat setempat yang belum mendapat respon.

Belajar dari berbagai permasalahan yang mengemuka ini dalam konteks hukum, keamanan, dan pertahanan kawasan perbatasan menunjukan bahwa tidak dapat dikesampingkan sebagai tolak ukur keupayaan mengembangkan pembangunan di kawasan perbatasan strategis.

\section{Potensi Objek Pariwisata Alam}

Pada konteks ini objek wisata alam merupakan potensi utama yang dapat mendatangkan potensi wisata baik lokal, nasional dan internasional. Kecamatan Pasir Limau Kapas merupakan daerah yang dinilai sangat potensial untuk dikembangkan. Ini disebabkan kawasan ini memiliki objek wisata perbatasan yang strategis seperti Pulau Jemur. Pulau Jemur adalah Pulau terindah yang berada di Kecamatan Pasir Limau Kapas yang memiliki daya tarik wisatawan dari Manca Negara maupun Lokal dan memiliki Panorama.

Pemandangan dan keindahan alam seperti Pantai berpasir putih yang bagus serta memiliki hewan langka yang dilindungi seperti Habitat Penyu Hijau dan Tempat Pengembang Biakan Anak Penyu Hijau yang terletak di Pulau Jemur, Pulau Jemur Juga memiliki Potensi Wisata diantaranya Goa Jepang, Menara Suar, Tapak Kaki Panglima Layar, Perigi Tulang, sisa pertahanan jepang, batu panglima layar, taman laut dan pantai berpasir putih emas.

Pulau Jemur memiliki Luas Wilayah 52,71 Ha dengan Jarak Tempuh kurang lebih 64 Mil dari Bagansiapiapi, lebih kurang 28 Mil dari Ibu Kota Panipahan, dan lebih 35 Mil dari Negara Tetangga yakni Malaysia. Sedangkkan jarak tempuh dari Tanjung Balai Asahan Provinsi Sumatera Utara lebih kurang 30 Mil. Dari jarak tempuh tampak bahwa Kepulauan ini bahwa jarak Ibu Kota lebih jauh berbanding jarak dari luar negeri. Realitas ini tentu saja berimplikasi serius jika saja Pulau Jemur mendapat klaim Malaysia sebagai bagian dari wilayahnya.

Sebagai kawasan perbatasan yang memiliki potensi wisata dapat diunggulkan menjadi penting pula jika Pemerintah Pusat memiliki kepedulian untuk menindaklanjuti programprogram yang telah dicanangkan. Ini penting dilakukan mengingat Pulau Jemur adalah gugusan pulau- pulau yang terdiri dari Pulau Jemur, Pulau Sarang Elang, Pulau Labuhan Bilik, Pulau Tukong Simbang, Pulau Batu Berlayar, Pulau Batu Adang, Pulau Batu Mandi, Pulau Tukong Mas, Pulau Tukong Perak, Pulau Kalironggo dan Pulau Pasir. Setidaknya berdasarkan data yang diperolehi terdapat 9 pulau yang merangkai menyatu menjadi Kepulauan Arwah Selat Melaka.

\section{SIMPULAN}

Potensi utama yang dimiliki Pasir Limau Kapas, seperti posisi geografis terkait kawasan strategis dan regulasi yang dihasilkan dinilai belum mendukung masalah pertahanan dan keamanan negara di perbatasan termasuk me- 
ngembangkan kawasan potensi objek wisata alam. Dari keempat potensi utama yang dimiliki adalah perwujudan dari terintegrasinya antara satu dengan yang lainnya. Dalam hubungan ini, perwujudannya tidak dapat dipisahkan antara satu dengan yang lain dalam hal mana yang lebih penting untuk diprioritaskan.

\section{DAFTAR RUJUKAN}

Adisasmita, Rahardjo. 2005. Dasar-Dasar Ekonomi Wilayah. Yogyakarta: Penerbit Graha Ilmu.

Albintani, Muchid. 2016. Berburu Rente di Pulau Batam: Provinsi Istimewa Singapura dan Negara. Yogyakarta: Deepubslish

Akaha, T. and Anna, V. (eds). 2005. Crossing National Borders: Human Migration Issues in Northeast Asia. Japan: United Nations University Press.

Amina, Siti. 2014. Kuasa Negara Pada Ranah Politik Lokal. Jakarta: Kencana Prenada Media Grup.

Bappenas. 2016. Kajian Pengembangan Kebijakan Asimetris dalam Pembangunan di Kawasan Perbatasan Negara. Direktorat daerah tertinggal, transmigrasi, dan perdesaan kementerian ppn/bappenas.

Blair, J.P. 1995. Local Economic Development Analysis and Practice. Canada: Sage Publication.

BKPM. 2011. Kajian Pengembangan Investasi Wilayah Perbatasan. Badan Koordinasi Penanaman Modal. 1-38.

Damanhuri.1990. Perencanaan Pembangunan Wilayah Terisolir. Yogyakarta: Piramida.

Daniel, M. 2002. Metode Penelitian Sosial Ekonomi. Jakarta: Bumi Aksara.

Djojodipuro, Marsudi. 1992. Teori Lokasi. Jakarta: Lembaga Penerbit Universitas Indonesia

Glasson, J. 1977. Pengantar Perencanaan Wilayah. Terjemahan Paul Sitohang. Jakarta: Penerbit LPFE-UI.

Green Cross, 2000. National Sovereignty and International Water Courses. Green Cross International, Hague.

Guo, R, 2004. Cross Border Resource Management, Regional Science
Association of China

Hajisarosa, Poernomosidi. 1978. Teori dan Strategis Pengembangan Wilayah untuk Negara R.I

Henrikson, A. K. 2000. Facing Across Borders: The Diplomacy of Bon Voisinage.

House, J. W. 1980. "The Frontier Zone: A Conceptual Problem for Policy Makers.”

Ishak, A. F. 2003. Membangun Wilayah Perbatasan Kalimantan dalam Rangka Memelihara dan Mempertahankan Integritas Nasional. Jakarta: Indomedia. Judistira. K.Gurun . 1999. Paradigma Sosial Budayadalam Pengembangan Masayarakat, makalah rapat Perbatasan Jateng - Jabar

Kencana Inu Syafiie. 2013. Ilmu Pemerintahan. Jakarta: Bumi Aksara.

Moleong, L.J. 2005. Metodologi Penelitian Kualitatif. Bandung: Remaja Rosdakarya.

Mahendra Putra K. 2010. Politik Hukum Pembangunan Kawasan Perbatasan Berbasis Teknologi Geospasial. Disertasi Doktor, Universitas Brawijaya Malang. Newman, D. 2006. The lines that continue to separate us: borders in our 'borderless' world. Progress in Human Geography 30 (2): pp. 143-161.

Nugroho, Iwan dan Dahuri, Rochmin. 2004. Pembangunan Wilayah Perspektif Ekonomi, Sosial dan Lingkungan. Jakarta: Penerbit Pustaka LP3ES.

Partnership. 2011. Kebijakan Pengelolaan Kawasan Perbatasan Indonesia. Partnership Policy Paper No. 2.

Prescott, J. R. V. Political Frontiers and Boundaries. London: Allen \& Unwin. Produk, 1987

Rodriguez, N. 1996. 'The Battle for the Border: Notes on Autonomous Migration, Transnational Communities, and the State'. Social Justice 23(3): 21-37.

Routlege. Rumford, C. 2006. 'Borders and bordering', in G. Delanty (ed.) Europe and Asia Beyond East and West: Towards a New Cosmopolitanism. London: Routledge.

Rasyid, Ryaas. 2000. Makna Pemerintahan, 
Jakarta: PT. Mutiara Sumber Widya. Sandy Nur Ikfal Raharjo. 2013. Kebijakan Pengelolaan Kawasan Perbatasan Darat Indonesia-malaysia (Studi Evaluatif di Kecamatan Entikong). Pusat Penelitian Politik, Lembaga Ilmu Pengetahuan Indonesia Widya Graha LIPI. Widyariset, Vol. 16 No.1, April: 73-80.

Tarigan, R. 2004. Ekonomi Regional Teori dan Aplikasi. Jakarta: Bumi Aksara.

Uiboupin, J. 2007. Cross border cooperation and economic development in border Van Well, L. 2006. Cross-Border Typologies in the Enlargement Area

Walters, W. 2006. Border Control. European Journal of Social Theory; 9; 187. London: Sage Publications.

www.bappenas.go.id. 2007. Rencana Induk Pengelolaan Kawasan Perbatasan Antar Negara Buku Utama, Prinsip Dasar, Arah Kebijakan, Strategi dan Program Pembangunan. Jakarta: Indonesia. 